\title{
Comment
}

\section{Exames da Ordem dos advogados do Brasil - OAB: Análise do Risco de falhas}

\author{
Artur Livônio Tavares de Sampaio ${ }^{1}$; Francisco das Chagas Rodrigues de Oliveira ${ }^{2}$
}

\begin{abstract}
Resumo: Tem como assunto central uma análise da possibilidade de falhas avaliativas do Exame da OAB. Além disso, expõe a classificação dos vários tipos de avaliações que existem. Seja quanto "a quem avalia", "a divisão do conteúdo" ou "quanto aos conteúdos". Obra essencialmente bibliográfica, trazendo os ensinamentos dos autores: Fábio Vieira Figueiredo, Marcelo Tadeu Cometti e Simone Diogo Carvalho Figueiredo. Se mostra de grande relevância, diante do enorme índice de reprovação dos graduados em Direito em todo o país.
\end{abstract}

Palavras chave: Avaliação Educacional; Ensino Jurídico; Exame da OAB.

\section{Exams of the Brazilian Bar Association - OAB: Failure Risk Analysis}

\begin{abstract}
Its central subject evaluative failures OAB exam. In addition, it exposes the classification of the various types of evaluations that exist. Be as " who evaluates " , " the division of content " or " as the contents ." essentially bibliographic work, bringing the teachings of the authors : Fabio Vieira Figueiredo, Marcelo Tadeu Cometti and Simone Diogo Carvalho Figueiredo. It is very important show in front of the huge failure rate of graduates in law throughout the country.
\end{abstract}

Keywords: Educational Evaluation ; Legal education ; OAB Exam.

\section{Introdução}

A avaliação educacional será detalhada ao longo desta obra, tendo como foco a avaliação realizada pelo Exame da OAB. Mas, antes de partir para esta avaliação específica, se faz necessário definir o que é avaliação. Desta forma, o ato de avaliar se refere a verificar determinada coisa, para saber o seu nível de qualidade. Podendo ser avaliada tanto uma pessoa física (Ex.: um aluno etc), como um objeto (Ex.: um produto; uma biblioteca etc).

Em primeiro lugar, serão expostas as várias modalidades de avaliação. Na classificação quanto "a quem avalia", a avaliação pode ser: "Interna" ou "Externa". E quanto "a divisão do conteúdo", teriam: a "Educacional” ou a "Institucional".

\footnotetext{
1 Advogado, mestrando em Educação, especialista em Direito Processual Civil (URCA-Crato), Direito das Famílias (URCA-Crato) e Direito Penal e Processual Penal (ESMAPE-Recife), atuando principalmente nas áreas: Trabalhista; Cível; de Família; e do Consumidor. E-mail: arturlivonio@yahoo.com.br

${ }^{2}$ Mestre em Gestão e Avaliação da Educação Pública pela UFJF (chicoverdemt@ gmail.com).
} 
Em seguida o enfoque se voltará para a avaliação realizada pela $\mathrm{OAB}$, com relação aos bacharéis em Direito que acabaram de se formar e desejam virar advogado. Várias falhas avaliativas serão mostradas ao longo da obra, a fim que seja buscado aprimoramento por parte da $\mathrm{OAB}$, na realização dos novos exames. $\mathrm{A}$ OAB é uma sigla, que significa "Ordem dos Advogados do Brasill", sendo o órgão de classe que regulamenta e fiscaliza os profissionais da área jurídica, que se graduaram em Ciência Jurídica (Direito) e, posteriormente, foram aprovados no Exame da OAB.

Este exame, inicialmente era realizado por cada seccional (OAB de cada unidade da federação). Depois ficou sendo feito pela CESPE. Mas, atualmente, a avaliação ficou a cargo da FGV (Fundação Getúlio Vargas).

Trabalho meramente bibliográfico, com autores como: Fábio Vieira Figueiredo, Marcelo Tadeu Cometti e Simone Diogo Carvalho Figueiredo.

Tema de grande relevância, diante do imenso número de faculdades de Direito existentes no país e do alto índice de reprovação no Exame da OAB. Algo precisa ser mudado, para que o Exame da OAB realize uma avaliação que de fato meça o nível de conhecimento dos que acabaram de concluir o curso jurídico.

\section{Tipos de Avaliação Educacional}

$\mathrm{O}$ ato de avaliar se refere a verificar determinada coisa, para saber o seu nível de qualidade. Podendo ser avaliada tanto uma pessoa física, quanto um objeto. Por exemplo, um funcionário de uma empresa ao ser fiscalizado pelo patrão, está sendo avaliado por ele. Em caso semelhante, um aluno, dentro de sala de aula é avaliado a todo instante pelo professor, seja quanto a participação (se faz ou não perguntas ao professor), a pontualidade (se chega atrasado ou não para a aula), a frequência (se falta muitos dias) e as notas dos exames (se tira notas boas ou não).

O INMETRO (Instituto Nacional de Metrologia, Qualidade e Tecnologia) também avalia os produtos que são colocados à disposição dos consumidores, verificando a durabilidade ("vida útil"), se existe o perigo de explosão ou de causar algum dano a saúde do usuário. 
Partindo agora para a "avaliação educacional", verificamos que a escola não é a ponta da avaliação e sim o "centro da avaliação". É nela onde os alunos estão constantemente sendo avaliados e que serão testados também no futuro, nos vestibulares, faculdades, órgãos de classe, pós-graduações, e, por fim, no mercado de trabalho.

A educação não é algo estático, exige mudanças para que a aprendizagem continue boa. Mas, muitas vezes, estas mudanças ocorrem de cima pra baixo, ou seja, o MEC determina uma mudança e os professores são obrigados a realizarem, não por acreditarem. Desta forma, agindo desmotivados, faz com que as metas não sejam alcançadas ou que, mesmo que se atinjam, demorem mais a ocorrerem. Sendo assim, tudo deve ser debatido e explicado a todos, pra só assim ser colocado em prática:

Entretanto, a maioria dos órgãos oficiais de educação e das instituições escolares promove mudanças diretivamente, de um momento para o outro, com os professores movidos pela obediência a regimentos, normas e determinações da administração, da supervisão, e não pelo espírito do engajamento. Não conseguem as mudanças desejadas, porque a aspiração e o entendimento de poucos não conseguem enfrentar o receio, a resistência, o conformismo de muitos. Mudar em educação, mudar em avaliação, exige "trocas de pele", pois envolve concepções e posturas de vida, e isso é penoso. Quando se coloca o educador diante de novas teorias, novas metodologias, ele é levado a responder: minha história, minha experiência, os conhecimentos que construí até hoje serão considerados tão valiosos quanto sempre o foram? O que mais me será pedido que "desaprenda"? Quanto tempo e esforço me custará a adaptação? (DEMO; TAILLE; HOFFMANN, 2010, p. 103)

Existem vários tipos de avaliações, por isso, passam por uma classificação. Tomando por base "quem avalia", podem ser classificadas em: "Interna" ou "Externa". E no que diz respeito "a divisão do conteúdo", teriam: a "Educacional" ou a "Institucional".

A “interna” é a realizada pela própria instituição de ensino, ou seja, a própria instituição com provas e trabalhos avaliando o aluno. Nesta, seria o professor avaliando o aluno. Já a “externa" é uma outra instituição avaliando aquela. Um exemplo da "avaliação interna" seria as provas de uma faculdade. Na externa, seria uma instituição de fora avaliando, uma instituição diferente da que o aluno está matriculado avaliando o aluno. Aqui também avalia os alunos, mais indiretamente teria como saber quantos alunos de uma instituição se saíram bem ou não. Pode-se mencionar, alguns exemplos de "avaliação externa": a prova da OAB e o ENEM (externa).

Como foi visto, a classificação quanto a divisão de conteúdo, pode ser: "Educacional" ou "Institucional". A "Educacional" avalia o desempenho educacional, por meio de testes. 
Enquanto que a "Institucional" avalia a estrutura do prédio, a biblioteca, a sala de aula, o estacionamento, através de questionários.

Na classificação "quanto aos conteúdos”, podem ser: Conceituais; Procedimentais; ou Atitudinais. A "conceitual é "o que se aprende", são as matérias, os assuntos, os conteúdos, como exemplo, como se inicia a República no Brasil ou o que é a Constituição. A “procedimental”, por sua vez, é "o que o aluno é", aqui é o aluno “aprender a fazer”, como saber comparar épocas da história ou saber se expressar na leitura, por exemplo. Por último, as "Atitudinais" é o "ser", coisas que o aluno interiorizou, que passou até a fazer parte de sua personalidade. Seria a dedicação ao estudo ou a curiosidade etc.

\section{Falhas Avaliativas do exame da OAB.}

A Ordem dos Advogados do Brasil possui a sigla OAB. Possui personalidade jurídica, mas não possui vínculo com a Administração Pública. Porém, apesar de não ser da Administração Pública, presta serviço público, por esta razão possui imunidade tributária. Em melhores palavras:

\footnotetext{
A Ordem dos Advogados do brasil é um serviço público e independente, dotado de personalidade jurídica e forma federativa, não mantendo nenhum vínculo funcional ou hierárquico com os órgãos da Administração Pública. Por constituir um serviço público, a OAB goza de imunidade tributária total em relação aos seus bens, rendas e serviços.
}

(FIGUEIREDO; COMETTI; FIGUEIREDO, 2015, p. 565)

A OAB possui várias finalidades, dentre eles: pugnar pela boa aplicação das leis; defender a Constituição, bem como, a ordem jurídica do Estado Democrático de Direito. E disciplinar, obviamente, a profissão de advogado em todo o território nacional. Assim sendo:

Tem por finalidade defender a Constituição, a ordem jurídica do Estado Democrático de Direito, os direitos humanos, a justiça social, e pugnar pela boa aplicação das leis, pela rápida administração da justiça e pelo aperfeiçoamento da cultura e das instituições jurídicas, e promover, com exclusividade, a representação, a defesa, a seleção e a disciplina dos advogados em toda a República federativa do Brasil. É privativo da Ordem dos Advogados do Brasil o uso da silha OAB. (FIGUEIREDO; COMETTI; FIGUEIREDO, 2015, p. 566) 
Id on Line Revista Multidisciplinar e de Psicologia

Id on Line Multidisciplinary and Psycology Journal

O Exame da OAB, também chamado de Exame de Ordem, encontra-se previsto no art. 8, inciso IV, da Lei n. 8.906, de 4 de julho de 1994 (Estatuto da Advocacia e a Ordem dos Advogados do Brasil). Deste modo, a aprovação no Exame da OAB trata-se de um dos prérequisitos para o graduado no curso de Direito, poder se tornar advogado. Como ensina:

Terão inscrição principal, todos aqueles que cumprirem integralmente os requisitos do art. 8, do EOAB, devendo ser efetuada perante o Conselho Seccional onde o candidato tenha seu domicílio profissional.

(FIGUEIREDO; COMETTI; FIGUEIREDO, 2015, p. 573)

A prova da $\mathrm{OAB}$ possui a primeira e a segunda fase. A primeira fase é constituída por 80 questões objetivas, contendo todas as disciplinas do Direito e a pessoa só faz a segunda fase, caso antes tenha sido aprovado na primeira fase. Não importa se o candidato tenha zerado determinada matéria, basta acertar 50\% das 80 questões, para ser aprovado na primeira fase. E, após ser aprovado na primeira fase, terá direito a fazer duas vezes a segunda fase, aí caso não passe na segunda, terá que voltar a fazer a primeira fase.

Já a segunda fase, é de um único ramo do Direito, escolhido pelo candidato no momento da inscrição no certame. Possui quatro questões subjetivas e uma questão prática, onde deve redigir uma peça jurídica. Esta segunda fase condiz mais com o estilo de provas realizadas nas graduações de Direito.

Contudo, as provas das faculdades são somente com questões subjetivas, inclusive, os alunos realizam os exames com os códigos em mãos. Já que não necessitam decorar as leis e sim saber manuseá-las e entendê-las, posto que todo advogado anda com um código.

$\mathrm{Na}$ contramão disso, mesmo as provas das faculdades de Direito sendo subjetivas (dissertativas), a primeira fase da OAB é toda com provas objetivas. Obrigando assim, que os novos bacharéis em Direito tenham que gastar dinheiro com cursinhos, para memorizar em curto espaço de tempo, tudo que viu durante toda a faculdade.

As faculdades estimulam os alunos mais a refletirem, já a prova da OAB cobra mais decorar (memória). Sendo assim, as provas deveriam ser mais condizentes com o que é visto nas faculdades e voltadas para a prática futura, destes que visam se tornar advogado. A visão de quem for elaborar as novas provas da $\mathrm{OAB}$, deve ser com conteúdo que façam os alunos refletirem e não meramente decorar. A título de exemplo, muitas vezes já se cobrou a quantidade de dias dos prazos, mas isso não precisa o advogado decorar, basta saber que medida legal deve aplicada para aquela situação e verificar a quantidade de dias no código. 
Mudanças devem ocorrer, a fim de aprimorar a avaliação, seja dentro das instituições de ensino, seja no Exame da OAB. Porém, um dos grandes problemas, quando se fala em alterar a maneira de avaliar, é o medo gerado pelas mudanças. Muitos professores se acomodam no que já sabem e ficam presos aquela velha técnica de ensino e de avaliação. Mesmo assim, não se pode esmorecer e achar que nada se conseguirá. A maioria das coisas da vida não são fáceis e toda inovação surgiu de uma mudança. Como bem expõe:

\begin{abstract}
O entusiasmo inicial de um grupo tende a esmorecer quando surgem as dificuldades, as "incongruências", a falta de recursos e os não saberes. Quando se elencam metas muito pretenciosas, os ânimos tendem a esmorecer, porque elas exigem muito tempo e não se percebe, então, que se esteja alcançando resultados que valham a pena o esforço. Assim, principalmente em avaliação, é importante começar por pequenas tentativas, como um leque de opções aos professores, divulgando-se permanentemente os êxitos e as dificuldades enfrentadas para o coletivo da escola. (DEMO; TAILLE; HOFFMANN, 2010, p. 114)
\end{abstract}

Por conseguinte, os elaboradores devem evitar provas objetivas no Exame de Ordem $(\mathrm{OAB})$, para que se assemelhe mais ao que foi realizado na época em que os alunos ainda estavam na graduação. E com conteúdo que de fato será usado futuramente na vida prática do aluno. Afinal, como se sabe, a educação é voltada para a ação, como a própria etimologia da palavra indica. E, não há sentido o candidato ter que voltar a fazer a primeira fase, caso não passe duas vezes na segunda fase, pois aqui não é concurso, que tem preenchimento de vaga. A OAB é apenas uma verificação de que o candidato possui o mínimo conhecimento aceitável para a prática advocatícia.

\title{
Considerações Finais
}

Espera-se que o leitor tenha captado o sentido de se realizar uma avaliação, bem como as modalidades de avaliações existentes e, ainda, as falhas na avaliação realidade por meio do Exame da OAB.

Assim como foi visto, existem vários tipos de avaliação, por isso são classificadas quanto: a "quem avalia" ("Interna" ou "Externa"); a "a divisão do conteúdo" ("Educacional" ou "Institucional"); e "quanto aos conteúdos" (Conceituais; Procedimentais; ou Atitudinais).

A OAB (Ordem dos Advogados do Brasil) é o conselho de classe da profissão de advogado. Este órgão, dentre outras atribuições, promove uma avaliação nos alunos que 
acabaram de se formar advogado. E, a depender da pontuação obtida neste exame, serão inscritos como advogados. Atualmente, a elaboração da prova é feita pela Fundação Getúlio Vargas, mas seguindo as regras determinadas pela OAB.

Na prova da $\mathrm{OAB}$ em vez de ser testado o conhecimento, se testa mais a memória, por cobrar detalhes que são encontrados facilmente nos códigos de leis, sem necessidade da pessoa memorizar para o exercício advocatício. Além disso, as faculdades estimulam os alunos mais a refletirem, já a prova da $\mathrm{OAB}$ cobra mais decorar (memória), posto que a primeira fase possui prova objetiva (de marcar).

Portanto, devem evitar provas objetivas no Exame de Ordem (OAB), para que se assemelhe mais ao que foi realizado na época em que os alunos ainda estavam na graduação. E com conteúdo que de fato será usado futuramente na vida prática do aluno.

\section{Referências}

FIGUEIREDO, Fábio Vieira; COMETTI, Marcelo Tadeu; FIGUEIREDO, Simone Diogo Carvalho. Teoria unificada. 6 ed. São Paulo: Saraiva, 2015.

DEMO, Pedro; TAILLE, Yves de La; HOFFMANN, Jussara. Grandes pensadores em educação: o desafio da aprendizagem, da formação moral e da avaliação. 5. ed. Porto Alegre: Editora Mediação, 2010.

\section{Como citar este artigo (Formato ABNT):}

SAMPAIO, A.L.T.; OLIVEIRA, F.C.R. Exames da Ordem dos advogados do Brasil - OAB: Análise do Risco de falhas. Id on Line Revista Multidisciplinar e de Psicologia, Janeiro de 2017, vol.10, n.33, p. 330-336. ISSN: 1981-1179.

Recebido: 06/12/2016

Aceito: 08/12/2016 